\title{
Analysis on Spatial Distribution of Rural Public Venues and Its Influencing Factors from Low-Carbon Perspective: Take Shijiaying Village as an example
}

\author{
Chunyang Yang *, Zhen Li \\ Department of Military Facility, Army Logistical University of PLA, Chongqing, China \\ *Corresponding Author.
}

\begin{abstract}
At present, rural areas are becoming the second largest source of greenhouse gas emissions, and it is imperative to explore a low-carbon construction and development model suitable for rural areas. In view of insufficient vitality of rural public venues, through a combination of field visits and investigations, ArcGIS spatial analysis and related mathematical statistics, the service range index and service distribution index of rural public venues are created, and Shijiaying Village, representative of the Guanzhong Plain area, is selected as an example to analyze the spatial distribution of its public venues. It is found that rural public venues present the overall characteristics of unbalanced spatial distribution, which are mainly manifested in the following aspects: first, administrative village-level public venues have small effective service range; second, there are distinctive differences in service distribution between different villages; third, rural public venues lack service in overall. Factors such as the distribution pattern of rural settlements, the location layout and type of the venues exert an important impact on the spatial distribution of rural public venues. The study is expected to provide a useful reference for the planning and construction of rural public venues and the quality improvement of human settlements in China in the new era.
\end{abstract}

Keywords: low-carbon, Rural public venue, spatial distribution, influencing factor, network analysis

\section{Introduction}

As an important carrier in villagers' activities such as production and life, communication, gatherings, festivals, etc. public venues are of great significance for improving rural development vitality and human settlement quality ${ }^{[1]}$. However, for a long time, due to labor population migration, lack of technical support, and insufficient capital investment, rural areas have been under "low-level and spontaneous" construction ${ }^{[2-3]}$, and public venues have gradually declined ${ }^{[4-5]}$. In recent years, with the vigorous advancement of the construction of new rural areas, continuous improvement has been made in rural public service facilities, but some newly-built public venues lose public attention, tending to desolate. In essence, they fail to provide effective service for villagers. How to avoid such problems is a task that needs to be urgently solved in the construction of new rural areas.

Scientific and reasonable spatial distribution is the main factor influencing service efficiency of rural public venues. However, the current related research content mainly focuses on the evolution of rural public venues $^{[6-8]}$, current situation analysis ${ }^{[9-12]}$ and optimization strategies ${ }^{[13-14]}$. Useful exploration has been made into evolution trend, existing problems and optimization development, but there are still some shortcomings. Seen from research methods, most existing research is qualitative research, lacking the introduction of quantitative methods, so that the proposed optimization strategies are often not universal. Seen from the perspective of research scale, the current research is mostly concentrated on large and medium scales such as provinces, cities and counties, and very little attention has been paid to the village scale. Seen from research content, there is very little in-depth analysis of material planning such as spatial distribution. In particle, research is insufficient on the factors affecting the spatial distribution of rural public venues, such as accessibility.

Therefore, this paper combines field visits and surveys, ArcGIS spatial analysis and mathematical statistics to analyze the spatial distribution of public venues in Shijiaying Village in the Guanzhong Plain by constructing a service scope index and a service distribution index. It then explores the factors influencing spatial

ISSN: 0010-8189 
distribution of rural public venues, with a view to providing useful reference for later rural planning and construction.

\section{Research Area, Data Sources and Methods}

\subsection{Research area}

Guanzhong Plain is located in central Shaanxi. The fertile plain is formed by the impact of the main branches of the Weihe River and the impact of the loess. It belongs to warm temperate semi-humid climate zone with an average annual temperature of $12-13.6^{\circ} \mathrm{C}$ and an annual precipitation of 550-660mm. The plain has fertile land, rich water systems, and relatively dense population, which has been an ideal place for human settlements since ancient times.

The Shijiaying Village selected herein is located in Fengxiang County, Baoji City, Shaanxi Province, in the west of the Guanzhong Plain. In 2019, the county has a registered population of 518,174, of which the rural population is 435,000 , accounting for $83.4 \%$ of the total population. Due to low level of urbanization, rural areas are the main residences of local people, among which public venues are relatively representative.

\subsection{Data sources}

Through field research, we can master basic data such as the number, type, and location of rural public venues. Using Ovi data map, rural roads, residential areas, public venues are plotted. Meanwhile, ArcGIS 10.3 was used to vectorize the data.

\subsection{Research methods}

\subsubsection{ArcGIS spatial analysis}

Network Analyst is one important function of ArcGIS Spatial Analysis, which is a method of geographic analysis based on a specific network such as transportation network ${ }^{15}$. Generally, rural planning is simple, and basic data is easy to access. This method has high calculation accuracy and conforms to reality, which enables acquisition of visualized service scope. This time, the service area analysis in the network analysis method is adopted, that is, the coverage area of the traffic street within the specified impedance range of the establishment points is simulated.

Regarding resistance model establishment, the "Technical Standards for Village Renovation" (GB/T50445-2019) points out that the layout of rural public venues should consider accessibility, and the service radius should not exceed 500m; "Urban Residential District Planning and Construction Standards" (GB50180-2018) stipulates that the service radius of activity facilities in communities and neighborhoods generally should not exceed $300 \mathrm{~m}$. Therefore, referring to the above-mentioned standards and combining the aggregation morphology characteristics of the administrative villages in the Guanzhong Plain, the service radius of public venues is set to $500 \mathrm{~m}$ outside the villages and $300 \mathrm{~m}$ inside the villages.

\subsubsection{Mathematical Statistics}

Through ArcGIS spatial analysis, the service area of rural public venues for each village and the entire administrative village can be calculated. By combining the venue types, the service distribution in each village's venues can be further calculated.

Calculate the service coverage index. The service scope index referred herein is the ratio of the service scope area of the public venues in the village to the village area. Through analysis, it is possible to calculate the service scope index $\mathrm{q}$ of public venues for each village and the overall service scope index $\mathrm{Q}$ for administrative villages. The formula is:

$$
\begin{gathered}
q=\frac{s^{\prime}}{s} \\
Q=\frac{\sum_{i=1}^{n} s_{n}^{\prime}}{\sum_{i=1}^{n} s_{n}}
\end{gathered}
$$

Where, $\mathrm{S}^{\prime}$ is the service area of public venues for a single village, $\mathrm{S}$ is the area of a single village, and $\mathrm{n}$ is the number of villages. 
Calculate the service distribution index. The distribution index $\mathrm{k}$ is a comprehensive index reflecting the distribution of public venues available for each village. A larger $\mathrm{k}$ value means better distribution of public venues in the village; A smaller $\mathrm{k}$ value means the opposite. The formula is:

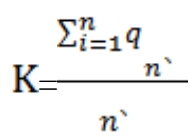

In the formula, $\mathrm{n}$ represents the type of all public venues in the administrative village.

\section{Empirical Case Analysis}

Shijiaying Village is affiliated to Chengguan Town of Fengxiang County. Located 2 kilometers northwest of the town government (Fig 1), it covers an area of 61,000 square kilometers. The main villages include Xiguan, Dongnianzitou, Xinianzitou, Beinianzitou, Nannianzitou, Shijiaying, Yuanjiazhuang, Zhanghuatai ${ }^{16}$. There are 14 villager groups under its jurisdiction, with a total of 1103 households, a total population of 4,442, and a permanent population of about 2,100. Agriculture is mainly based on the cultivation of wheat and corn. As Xiguan and Zhanghuatai have undergone urbanization, they are not included in the research scope. Field surveys were conducted on the remaining 6 villages in April 2020 (Fig 2).

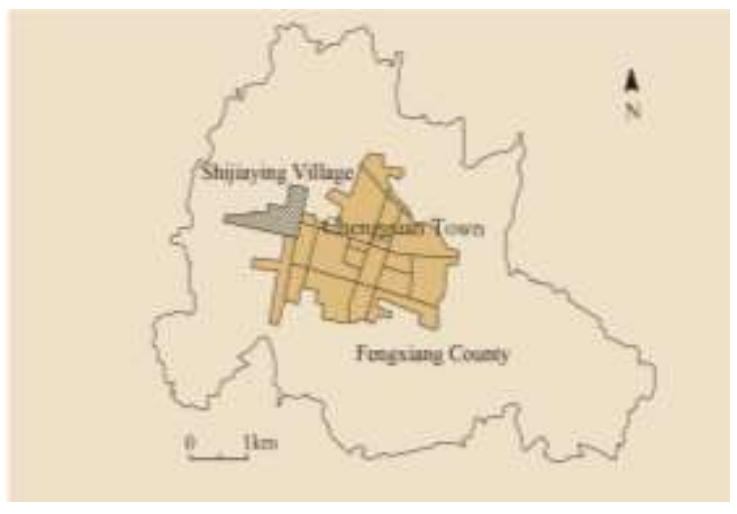

Fig 1: Geographical location of Shijiaying Village

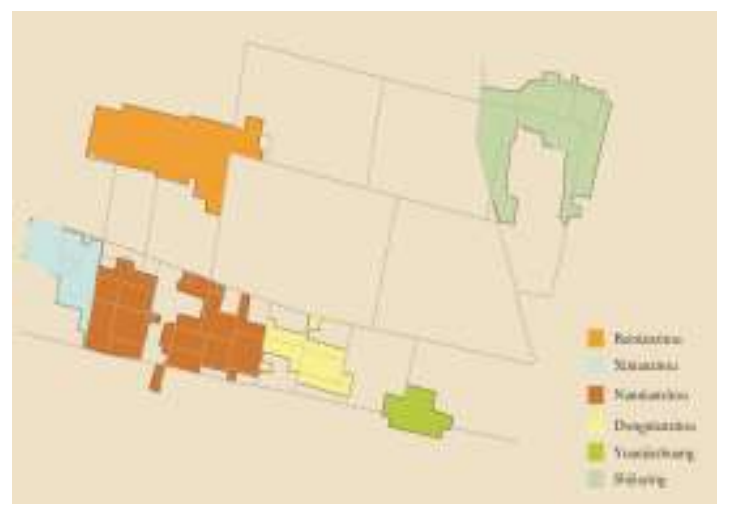

Fig 2: Distribution of Shijiaying Village

3.1 Overview of public venues

The existing public venues in Shijiaying Village mainly include cultural and sports activity squares, fitness squares, cultural stations, temples, chess and card rooms, and streets (Fig 3).

The author made visits and observations on working days and holidays, and found that the village's public venues have poor performance in overall. For example, cultural and sports activity squares and cultural stations basically fail to perform their service roles. Almost no one cares about them, and the villagers do not know the relevant construction progress; while the fitness squares, chess and card rooms and temples built by the villagers have relatively good use effect, but limited to the venue attributes, user population is single; streets and lanes are the public venues most frequently used by villagers in daily life, which have the largest number of participants and the widest time range, especially at some intersections, village entrances, and spaces in front of houses. 


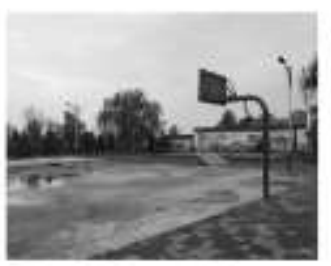

Coltural and Spots Activity square.

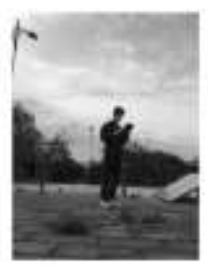

Fitness square

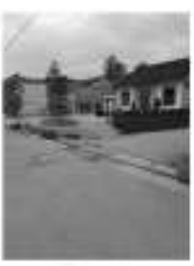

Temple

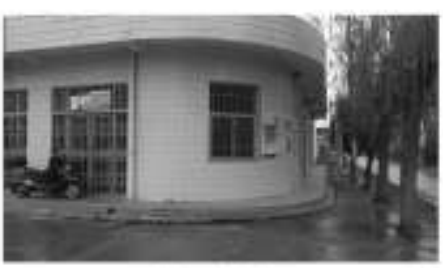

Cultural Station

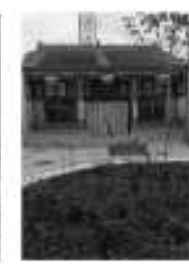

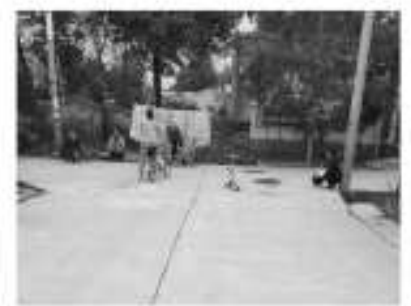

Strocts and lane

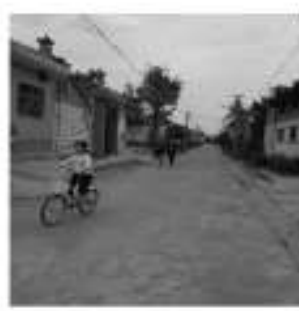

Chess and Cands Roon

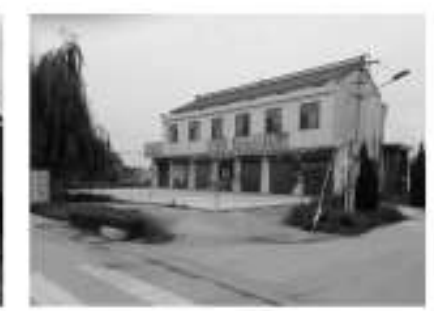

Fig 3: Shijiaying village public activity place

\subsection{Spatial distribution}

\subsubsection{Analysis of service scope}

Through the service area analysis in the ArcGIS network analysis method, the service scope of Shijiaying Village's cultural and sports activity square, fitness square, cultural station, temple, chess and card room are simulated respectively.

When determining the service radius, the cultural and sports activity square, chess and card room, and cultural station are all located outside the village, so the resistance value is set to $500 \mathrm{~m}$; the fitness square and temple are inside the village, and the resistance value is set to $300 \mathrm{~m}$. By establishing network data set, the service scope of each public venue is obtained (Fig 4).

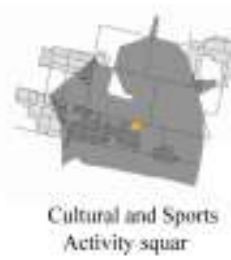

Activity squar

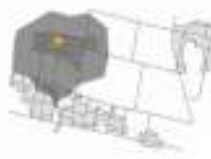

Filness square

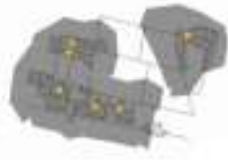

Temple

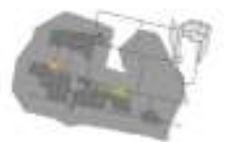

Cbess and Cands Room

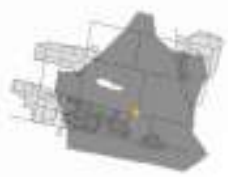

Cultural Station

The siles of public activity place

Fig 4: Analysis of service scope of public activity places

3.2.2 Calculation of Service Scope Index

To gain a more intuitive understanding of the service scope of each public venue, we respectively calculate the service scope index $\mathrm{q}$ and the overall service scope index $\mathrm{Q}$ of the public venue in each village, and make quantitative analysis of its service scope (Table 1).

Table 1 Calculation table of service scope index of public activity places

\begin{tabular}{|c|c|c|c|c|c|}
\hline Village & $\begin{array}{c}\text { Cultural and } \\
\text { Sports Activity } \\
\text { square }\end{array}$ & Fitness square & $\begin{array}{c}\text { Cultural } \\
\text { Station }\end{array}$ & Temple & $\begin{array}{c}\text { Chess and } \\
\text { Cards } \\
\text { Room }\end{array}$ \\
\hline Beinianzitou & 0.19 & 1 & 0.05 & 1 & 1 \\
\hline Xinianzitou & 0 & 0.05 & 0 & 1 & 1 \\
\hline Nannianzitou & 0.68 & 0.08 & 0.5 & 1 & 1 \\
\hline Dongnianzitou & 1 & 0 & 1 & 1 & 1 \\
\hline Yuanjiazhuang & 1 & 0 & 1 & 0.26 & 1 \\
\hline Shijiaying & 0.04 & 0 & 0.18 & 1 & 0 \\
\hline Overall service & 0.38 & & 0.33 & 1 & 0.75 \\
\hline
\end{tabular}

ISSN: 0010-8189

(C) CONVERTER 2020 
By comparing the service scope indexes of various public venues, it can be seen that there are great differences in service scope indexes of the main public venues in Shijiaying Village, and the service scope level of the main venues is relatively low.

Cultural and sports activity squares and cultural stations are public venues at the administrative village level, whose overall service scope index is only 0.38 and 0.33 , respectively. For the three villages of Beinianzitou, Xinianzitou, and Shijiaying, the service scope index is less than 0.20. Xinizitou even has no service coverage.

The service scope index of chess and card rooms is 0.75 . Except for the remote Shijiaying, which is not covered, the service scope index of other villages has reached 1.

The service scope index of both fitness square and temple reaches 1 . Considering that they are located within each village group, with local villagers as the main service targets, $S$ is taken as the area of the village itself when calculating the service scope index. In addition, the fitness square provides certain service for Xinianzitou and Nannianzitou, while the temples in Dongnianzitou provide certain service for Yuanjiazhuang.

\subsubsection{Calculation of service distribution index}

After obtaining the service scope index of each public venue, to further analyze the distribution in each village, the service distribution index is calculated for each village.

When determining the venue types, consideration is given to the fact that the existing public venues in Shijiaying Village mainly include cultural and sports activity squares, fitness squares, cultural stations, temples, and chess and card rooms (Table 2).

Table 2 Calculation table of distribution index of public activity places

\begin{tabular}{|c|c|c|c|c|c|c|}
\hline Village & $\begin{array}{c}\text { Beinian } \\
\text { zito }\end{array}$ & $\begin{array}{c}\text { Xinian } \\
\text { zito }\end{array}$ & $\begin{array}{c}\text { Nannian } \\
\text { zito }\end{array}$ & $\begin{array}{c}\text { Dongnian } \\
\text { zito }\end{array}$ & $\begin{array}{c}\text { Yuanjia } \\
\text { zhuang }\end{array}$ & Shijiaying \\
\hline Village site type & 3.24 & 2.05 & 3.26 & 4 & 3.26 & 1.22 \\
\hline $\begin{array}{c}\text { Types of administrative } \\
\text { village sites }\end{array}$ & \multicolumn{7}{|c|}{5} \\
\hline $\begin{array}{c}\text { Service Distribution } \\
\text { Index }\end{array}$ & 0.65 & 0.41 & 0.65 & 0.8 & 0.65 & 0.24 \\
\hline
\end{tabular}

According to the analysis results, there are big differences in service distribution index of public venues in Shijiaying Village, and the venue distribution is uneven in each village.

Shijiaying and Xinianzitou have single-type available public venues in a small number. Where, Shijiaying has only one temple located inside the village, with a service distribution index of only 0.24 ; while Xinianzitou itself has no activity venues, only Nannianzitou's temples and chess and card rooms provide certain service for it, with a distribution index of only 0.41 .

Yuanjiazhuang, Beinianzitou and Nannianzitou have ordinary public venue distribution effect, with a service distribution index of 0.65 . Where, Yuanjiazhuang mainly has cultural stations and cultural and sports activity squares to provide effective services; Beinianzitou Village has built temples and fitness squares within the village, and the chess and card room outside the village can also provide effective services; Nannianzitou Village has cultural and sports activity squares and cultural stations in addition to temples to provide certain services.

The public venues available in Dongnianzitou are relatively well distributed, with a service distribution index reaching 0.8. Except the fitness square, all the other four venues can provide effective services for it.

\subsection{Overall characteristics}

Through the above analysis, it can be found that although the number and types of existing public venues in 
Shijiaying Village are relatively complete, the overall spatial distribution is uneven. It is mainly manifested in the following aspects: First, administrative village-level public venues have small effective service scope; second, the spatial distribution of public venues is obviously different between different villages; third, the overall public venues in the village lack of services. As a result, local rural public venues have relatively low service efficiency, and the public services available for villagers are uneven, which affects the overall quality development of rural human settlements.

\section{Influencing Factors}

\subsection{Distribution patterns of rural settlements}

The Guanzhong Plain area is suitable for human survival thanks to its natural geographical environment, which has flat terrain, pleasant climate, high density of rural settlements, and large average population scale $^{17}$. Villages dominated by agricultural production are generally randomly distributed in the vast Guanzhong Plain in clusters and groups. At the same time, the plain area is strategically indefensible, so the aggregation form helped the village defense in ancient times ${ }^{18}$. Shijiaying Village basically retains the traditional and typical settlement patterns in the Guanzhong Plain, which are distributed in "four large and one small" groups.

However, such randomly scattered clusters have brought certain difficulties to the site location and layout of public venues. Due to the large number of villages subordinate to administrative villages in scattered distribution, it is difficult for the public venues of administrative villages to achieve even coverage of services in each village. The great differences in public services enjoyed by villagers go against the overall construction and development of the villages.

\subsection{Site selection and layout of the venues}

Whether the site selection and layout is scientifically and reasonably adapted to local conditions is also a main factor affecting the spatial distribution of rural public venues. The traditional village roads in Guanzhong area have dense internal road network, and the public venues are generally located in the village center $^{19}$, which allows villagers to use public facilities together, saves land to the greatest extent, and at the same time guarantees basically consistent cultivation radius. The traditionally preserved temples in Shijiaying Village and the fitness squares spontaneously built by villagers in recent years have adopted a "small-scale, scattered-point" model. Despite the small coverage and single functional facilities, the service scope can effectively cover the village, so that the public venues of each village are basically balanced.

At present, the planning and construction of rural public venues led by the government are mainly at the administrative village level, usually relying on village committees. Cultural and sports activity squares and cultural stations adopt a "large-scale, centralized" model. Despite the relatively complete functional facilities, the effective service scope is small, and the service scope is uneven for each village. At the same time, seen from the observation results of the previous visits, the use efficiency is much lower than the former.

\subsection{Types of venues}

For a long time, rural public infrastructure facilities have slow development and renewal, venues have incomplete facilities, which has affected the quality improvement of rural human settlements. In recent years, the government has begun to invest in the construction of a number of administrative village-level public venues, such as cultural stations, cultural and sports activity squares, etc. According to analysis, although the public activities in surrounding villages have been effectively enriched, the overall service quality is not high.

At the same time, seen from self-construction and development of each village, as the primary young and middle-aged labor force in the countryside constantly shifts to cities, the permanent population is mainly middle-aged and old people as well as children. The low production and consumption level results in a low level of self-construction and development. In Shijiaying Village, except that the traditional temples are basically retained in the villages, only Beinianzitou built a small fitness square in front of the temple. The overall public venues are of a single type, and there is a lack of activity facilities for the principal users of 
elderly and children, making it difficult to meet the villagers' actual needs and the requirements of constructing rural cultural life in the new countryside.

\section{Conclusion}

Through a combination of field visits and investigations, ArcGIS spatial analysis and related mathematical statistics, the service range index and service distribution index of rural public venues are created, and Shijiaying Village, representative of the Guanzhong Plain area, is selected as an example to analyze the spatial distribution of its public venues. It is found that rural public venues present the overall characteristics of unbalanced spatial distribution, which are mainly manifested in the following aspects: first, administrative village-level public venues have small effective service range; second, there are distinctive differences in service distribution between different villages; third, rural public venues lack service in overall. Factors such as the distribution pattern of rural settlements, the location layout and type of the venues exert an important impact on the spatial distribution of rural public venues. The above conclusions are expected to provide a useful reference for the planning and construction of rural public venues and the quality improvement of human settlements in China in the new era.

Of course, by selecting an administrative village in the Guanzhong area for empirical analysis, the study has certain limitations. Factors such as the clustering and distribution of villages as well as site location and layout of public venues have respective particularities. In addition, this paper fails to discuss optimization strategies for spacing and location of rural public venues in Guanzhong area. With the gradual improvement in basic information of local villages, there will be clearer feature classification of the rural clusters in the Guanzhong area, and more complete optimization measures and quantitative indicators will be formed in site selection of rural public venues.

\section{References}

[1] Z.D. Lei. "Integration and Reconstruction: A Study on the Transformation of Guanzhong Rural Settlements," Southeast University Press, 2009.

[2] K. Liu. "Research on Rural Public Open Space in China," Tsinghua University, 2012.

[3] X.M. Li. "Research on improvement and planning strategy of rural human settlement environment in Guanzhong area," Xi'an University of Architecture and Technology, 2018.

[4] Y. Xu, Y. Wu, L. Sun, et al., "Rural Social Observation (Five Sections)," Zhejiang Academic Journal, no. 2, pp. 90-98, 2002.

[5] L. Zhang. "The Decline and Reconstruction of Rural Public Space: Also on Rural Social Integration," Journal of Tianjin Administration Institute, vol. 15, no. 6, pp. 33-37, 2013.

[6] H.L. Cao. "Village public space amid social changes in rural areas: An empirical study on the reconstruction of village order with Subei Yao Village as an example," China Rural Survey, no. 66, pp. 63-75, 2005.

[7] L.M. Dong. "The shrinkage and expansion of village public space," Journal of Jiangsu Administration Institute, no. 5, pp. 51-57, 2010.

[8] L.P. He. "Viewing the weakening of rural social control from the perspective of public space," Theory and Modernization, no. 2, pp. 100-104, 2008.

[9] K.R. Lu, C. Cheng. "The public space changes and the rural inheritance culture of traditional villages: Taking three villages in Zhejiang as an example," Journal of Guangxi University for Nationalities (Philosophy and Social Sciences Edition), no. 6, pp. 28-35, 2016.

[10] C.C. Wang, Y. Kong, G.B. Li. "Research on the evolution characteristics and driving mechanism of rural public space," Modern Urban Research, no. 4, pp. 5-9, 2014.

[11] L.L. Dai, H.T. Xu. "The formation motivation, system composition and development changes of the public space of historical and cultural villages in the suburbs of Beijing," Beijing Planning Review, no. 3, pp. 72-76, 2010.

[12] C. Yang. "Research on the public space of traditional villages in North Hainan Island from the perspective of communicative behavior," Hainan University, 2018.

[13] Y.L. He, P. Yang, H. Wei. "Research on the optimization strategy for rural public space based on 
villagers' needs," Furniture \& Interior Design, vol. 253, no. 3, pp. 43-45, 2020.

[14] Y. Lu, L. Qin. "Reassociated Society-Planning and Construction of Rural Public Activity Center," Urbanism and Architecture, no. 12, pp. 43-45, 2012.

[15] L.Q. Gao. "Research on mountainous city green space layout based on spatial accessibility," Southwest University, 2010.

[16] “Geographical Names of Fengxiang County,” Baoji, 2019.

[17] X.J. Chen, Z.X. Chen. "A preliminary study on the spatial structure of rural settlements in Guanzhong area, Shaanxi," Journal of Northwest University (Natural Science Edition), no. 5, pp. 478-485, 1993.

[18] H.T. Yin, Z.X. Chen. "The distribution characteristics and evolution of rural settlements in Shaanxi," Human Geography, no. 4, pp. 17-24, 1995.

[19] S.C. Feng. "Research on the spatial morphological characteristics of traditional villages in Guanzhong area," Chang'an University, 2015. 